\title{
STRATEGI PENGEMBANGAN POLA HIDUP BERSIH DAN SEHAT (PHBS) DALAM MENGANTISIPASI PENYAKIT BERBASIS LINGKUNGAN (PBL)
}

\author{
Mimatun Nasihah', ${ }^{1}$ Istianah $^{2}$, Anggreani Ayu Saraswati $^{3}$ \\ Kesehatan Lingkungan, Fakultas Ilmu Kesehatan, Universitas Islam Lamongan \\ Jl. Veteran No.53A Lamongan \\ mima@unisla.ac.id ${ }^{1}$, aisti262@gmail.com ${ }^{2}$, anggreanisaras@gmail.com ${ }^{3}$
}

\begin{abstract}
ABSTRAK
Saat ini pesantren berlomba-lomba memiliki infrastruktur modern, tetapi hanya beberapa pesantren yang menerapkan life-stlye modern. Masih banyak pesantren yang melestarikan kultur tradisional dimana santri di pesantren tersebut dituntut untuk berperilaku sesuai life-style tradisional demi melestarikan kultur tersebut. studi ini dimaksudkan memahami perilaku kesehatan di pesantren, yang berfokuskan tentang bagaimana memahami perilaku pemeliharaan kesehatan santri, memahami perilaku pencarian dan penggunaan sistem pelayanan kesehatan santri, memahami perilaku kesehatan lingkungan, dan rasionalisasi, tindakan sosial terhadap perilaku hidup sehat dan bersih santri di pondok pesantren Ihyaul Ulum Dukun Gresik. Dari hasil studi didapatkan, bahwa respon santri terhadap perilaku kesehatan masih kurang dipandang dari sudut pandang medis modern, karena pesantren memiliki kultur yang berbeda dengan masyarakat diluar pesantren.Hal ini terlihat dari pertama, dalam memelihara kesehatan, santri masih mempertahankan diri dari penyakit dan menjaga kesehatan masih dengan cara yang sederhana. Kedua, dalam usaha memanfaatkan sistem kesehatan, santri mengacu pada pengetahuan kesehatan yang santri pahami.Ketiga, perilaku kesehatan lingkungan santri dipengaruhi erat struktur dan nilai-nilai budaya serta nilai-nilai religi yang ada dipesantren.Keempat, usaha rasionalisasi PHBS, dengan menyesuaikan dengan nilai-nilai kultural dan religi di pesantren guna meningkatkan derajat kesehatan santri.
\end{abstract}

Kata Kunci: Pondok Pesantren, PHBS, PBL

\begin{abstract}
At present pesantren are competing to have modern infrastructure, but only a few pesantren apply modern life-stlye. There are still many Islamic boarding schools that preserve traditional culture where students in Islamic boarding schools are required to behave according to traditional lifestyle in order to preserve the culture. This community service is intended to understand health behavior in Islamic boarding schools, which focuses on how to understand the health maintenance behavior of students, understand the search behavior and use of santri health service systems, understand environmental health behaviors, and rationalization, social actions to healthy and clean living behavior of santri in Ihyaul Islamic boarding schools. From the results of the study, it was found that the santri's response to health behavior was still less from a modern medical point of view, because the pesantren had a different culture than the community outside the pesantren. This is seen from: First, in maintaining health, santri still defend themselves from diseases and maintain their health in a simple way. Second, in an effort to utilize the health system, santri refer to the health knowledge that students understand, Third the behavior of santri's environmental health is influenced closely by the structure and cultural values and religious values of the existing Islamic boarding schools. Fourth, efforts to rationalize PHBS, by adjusting to cultural and religious values in the pesantren to improve the health status of santri.
\end{abstract}

Keywords: Islamic Boarding School, Clean and Healthy Lifestyle (CHL), Environment Based Illness (EBI) 


\section{PENDAHULUAN}

Kesehatan merupakan kondisi dimana kita berada jauh atau terbebas dari penyakit. Mencegah sakit adalah lebih mudah dan murah dari pada mengobati seseorang apabila jatuh sakit. Salah satu cara untuk mencegah hal tersebut adalah dengan bergaya hidup sehat. Gaya hidup sehat adalah segala upaya untuk menerapkan kebiasaan yang baik dalam menciptakan hidup yang sehat dan menghindarkan kebiasaan buruk yang dapat mengganggu kesehatan. Salah satu contoh akibat kebiasaan buruk tersebut seperti semakin banyaknya penderita penyakit menular seperti scabies (penyakit kulit), kudis, diare, ISPA. Hal ini juga sering di alami para santri di ponpok pesantren. Sehingga tidak jarang istilah perilaku hidup bersih dan sehat (selanjutnya disingkat menjadi PHBS) terdengar di pesantren dikarenakan kondisi yang sangat mendukung terjadinya penyebaran penyakit dikarenakan gaya hidup sehat yang diterapkan dilingkungan tersebut. (Ratnasari, 2011).

PHBS merupakan sekumpulan perilaku yang dipraktikkan atas dasar kesadaran sebagai hasil pembelajaran yang menjadikan seseorang atau keluarga dapat menolong diri sendiri di bidang kesehatan dan berperan aktif dalam mewujudkan kesehatan masyarakatnya (Pratama, 2009). Indikator tatanan perilaku hidup bersih sehat terdiri dari indikator perilaku dan indikator lingkungan di enam tatanan, yaitu tatanan rumah tangga, tatanan tempat kerja, tatanan tempat umum, tatanan sekolah, tatanan sarana kesehatan dan tatanan pondok pesantren (UPTD Puskesmas Dinoyo, 2011)

Pondok Pesantren modern mengajarkan pendidikan umum atau formal, dimana persentase ajarannya lebih banyak ilmu-ilmu pendidikan agama Islam dan ilmu umum (matematika, fisika, dan lainnya).Ini sering disebut dengan istilah pondok pesantren modern, dan umumnya tetap menekankan nilai-nilai dari kesederhanaan, keikhlasan, kemandirian, dan pengendalian diri.Pada pesantren dengan materi ajar campuran antara pendidikan ilmu formal dan ilmu agama Islam, para santri belajar seperti di sekolah umum atau madrasah. Pesantren campuran untuk tingkat SMP kadang-kadang juga dikenal dengan nama Madrasah Tsanawiyah, sedangkan untuk tingkat SMA dengan nama Madrasah Aliyah. Namun, perbedaan pesantren dan madrasah terletak pada sistemnya.Pesantren memasukkan santrinya ke dalam asrama, sementara dalam madrasah tidak. (Depag, 2003)

Pondok pesantren, selain dikenal sebagai wahana tempat belajar santri dan santriwati dalam mendalami ilmu agama Islam, namun dalam melaksanakan pengelolaan pondok pesantren, masih ada faktor-faktor lain yang menjadi ciri khas yang menonjol di kalangan 
masyarakat pesantren, terutama di masa lampau.Problema itu adalah kebersihan di lingkungan pondok pesantren yang terkenal kotor, kumuh, tidak higienis. (Noor;2006)

Menurut Ikhwanudin, 2010 faktor yang menentukan rendahnya kualitas perilaku kesehatan santri adalah peraturan pondok, fasilitas pondok, dan teman dekat di pondok. Kondisi sanitasi pada Ponpes akan sangat berkaitan dengan angka kesakitan berbasis lingkungan yang menular. Beberapa masalah sanitasi sangat umum di Ponpes dapat kita sebut antara lain keterbatasan sarana sanitasi dan perilaku santri yang belum ber PHBS.

Berdasarkan ulasan diatas, diketahui bahwa masih banyak permasalahan-permasalahan perilaku hidup bersih dan sehat pada tatanan di pondok pesantren.Hal ini ditunjukan pada keterbatasan sarana sanitasi dan perilaku santri yang belum ber PHBS.Sehingga dari latar belakang inilah penulis tertarik melakukan pengabdian masyarakat berupa promosi kesehatan di pondok pesantren Ihyaul Ulum di Kecamatan Dukun Kabupaten Gresik tentang Strategi Pengembangan PHBS dalam Mengantisipasi Penyakit Berbasis Lingkungan.

\section{METODE}

\section{Metode Pelaksanaan}

Jenis kegiatan ini yaitu dalam bentuk sosialisasi, deskriptif, kolerasional dan survei

\section{Jadwal Pelaksanaan}

\section{Tabel 1.Jadwal Pelaksanaan Pengabdian Masyarakat}

\begin{tabular}{|l|l|l|l|l|}
\hline N & \multirow{2}{*}{ O } & \multicolumn{2}{|c|}{ JENIS KEGIATAN } & \multicolumn{3}{|c|}{ WAKTU } \\
& & FENELITIAN \\
\cline { 3 - 5 } & & Meb & Apr \\
\hline 1 & $\begin{array}{l}\text { Persiapan penentuan judul } \\
\text { pengabdian masyarakat }\end{array}$ & & & \\
\hline 2 & Pembekalan materi & & & \\
\hline 3 & Perzinan ke instansi & & & \\
\hline 4 & $\begin{array}{l}\text { Pelaksanaan Pengabdian } \\
\text { Masyarakat }\end{array}$ & & & \\
\hline
\end{tabular}

\section{Waktu dan tempat pelaksanaan}

Pengabdian Masyarakt ini dilaksanakan di Pondok Pesantren Ihyaul Ulum Kecamatan Dukun Kabupaten Gresik pada 22 April 2019 pukul 15:15 WIB- Selesai 


\section{HASIL DAN PEMBAHASAN}

\section{Hasil}

Tabel 2. Hasil Pengabdian Masyarakat "Strategi Pengembangan Pola Hidup Bersih dan Sehat (PHBS) dalam Mengantisipasi Penyakit Berbasis Lingkungan (PBL)

\begin{tabular}{|c|c|c|c|}
\hline $\begin{array}{l}\mathbf{N} \\
\mathbf{0}\end{array}$ & Kegiatan & $\begin{array}{c}\text { Hambatan/Faktotr } \\
\text { yang } \\
\text { Mempengaruhi }\end{array}$ & $\begin{array}{c}\text { Penerapan } \\
\text { PHBS }\end{array}$ \\
\hline 1 & $\begin{array}{l}\text { Melakukan } \\
\text { piket setiap hari } \\
\text { 1x sebelum } \\
\text { tidur }\end{array}$ & $\begin{array}{l}\text { Jika dibersihkan } \\
\text { setelah bangun tidur } \\
\text { maka menjadi } \\
\text { percuma karena akan } \\
\text { kotor lagi }\end{array}$ & Belum \\
\hline 2 & $\begin{array}{l}\text { Membuang } \\
\text { sampah di } \\
\text { dalam kamar }\end{array}$ & $\begin{array}{l}\text { Jauh dari tempat } \\
\text { pembuangan sampah }\end{array}$ & Belum \\
\hline 3 & $\begin{array}{l}\text { Meletakkan } \\
\text { gantungan baju } \\
\text { di setip dinding }\end{array}$ & $\begin{array}{l}\text { Kurangnya fasilitas } \\
\text { tempat peletakkan } \\
\text { baju }\end{array}$ & Belum \\
\hline 4 & $\begin{array}{l}\text { Membersihkan } \\
\text { kamar mandi } \\
\text { setiap } 1 \text { minggu } \\
\text { 1X }\end{array}$ & $\begin{array}{l}\text { Sesuai jadwal } \\
\text { piket/Ro'an }\end{array}$ & Sudah \\
\hline 5 & $\begin{array}{l}\text { Melakukan cuci } \\
\text { tangan sehabis } \\
\text { makan dan } \\
\text { memakai sabun }\end{array}$ & $\begin{array}{l}\text { Hanya sekedar } \\
\text { mencuci tangan tanpa } \\
\text { memakai sabun }\end{array}$ & Belum \\
\hline 6 & $\begin{array}{l}\text { Menggunakan } \\
\text { alat pribadi } \\
\text { sebagai alat } \\
\text { kebetuhan } \\
\text { bersama }\end{array}$ & Karena kebiasaan & Belum \\
\hline
\end{tabular}

\section{Pembahasan}

\section{Faktor Lingkungan}

Moenir (1992) mengemukakan bahwa sarana adalah segala jenis peralatan, perlengkapan kerja dan fasilitas yang berfungsi sebagai alat utama/pembantu dalam pelaksanaan pekerjaan, dan juga dalam rangka kepentingan yang sedang berhubungan dengan organisasi kerja. Sarana dan prasarana adalah merupakan seperangkat alat yang digunakan dalam suatu proses kegiatan baik alat tersebut adalah merupakan peralatan pembantu maupun peralatan utama, yang keduanya berfungsi untuk mewujudkan tujuan yang hendak dicapai. 
Air merupakan hal yang paling esensial bagi kesehatan, tidak hanya dalam upaya produksi tetapi juga untuk konsumsi domestik dan pemanfatannya (minum, masak, mandi, dan lain -lain). salah satu faktor penting yang berpengaruh pada praktik PHBS adalah fasilitas sanitasi yang tercermin dari akses masyarakat terhadap air tempat pembiangan sampah dan sanitasi dasar.

Hasil observasi dan promosi menunjukkan bahwa perilaku kebersihan diri santri di Pondok pesantren Ihyaul Ulum Kecamatan Dukun Kabupaten Gresik dengan kategori baik $68 \%$, lebih banyak dibandingkan dengan kategori kurang baik 32\%. Di pondok Pesantren kecenderungan tertular penyakit kulit sebab kurangnya kebersihan diri sangat tinggi.Penyebabnya adalah tinggal bersama dengan sekelompok orang seperti di pesantren memang berisiko mudah tertular berbagai penyakit kulit, khusunya penyakit scabies.Penularan terjadi bila kebersihan pribadi dan lingkungan tidak terjaga dengan baik.Masih ada pesantren yang tumbuh dalam lingkungan yang kumuh, tempat mandi dan WC yang kotor, lingkungan yang lembab, dan sanitasi yang buruk. Ditambah lagi dengan perilaku yang tidak sehat, seperti menggantung pakaian dalam kamar, tidak membolehkan santri wanita menjemur pakaian di bawah terik matahari, dan saling bertukar benda pribadi, seperti sisir dan handuk

Dapat dikatakan bahwa santri telah mengetahui mana yang baik untuk kesehatan dirinya, tetapi dalam mewujudkannya dalam perilaku masih juga buruk. Hal ini disebabkan karena kebiasaan individu yang berbeda. Kemungkinan lain efesiensi untuk melakukan kebersihan diri kurang mendapat perhatian dari lingkungannya. Perilaku santri dalam melakukan kebersihan diri akan lebih mudah apabila santri tersebut mengetahui manfaat melakukan kebersihan diri, tahu cara melakukan kebersihan diri yang benar dan tahu akibat atau dampak apabila tidak melakukan kebersihan diri. Perilaku juga akan dipermudah apabila santri yang bersangkutan mempunyai sikap yang positif terhadap perilaku kebersihan diri. Ditemukan pada kelompok santri yang berusia 13-15 tahun yaitu 40\%, dan yang berusian 16-18 tahun yaitu 45\% dibandingkan dengan kelompok santri yang berusia 19-23 tahun yaitu $15 \%$. Adanya perubahan umur tidak berdampak adanya perubahan perilaku.Pada umur 16-23 tahun seharusnya dapat berperilaku baik dibandingkan dengan umur 13-15 tahun.Kebersihan diri (personal hygiene) dilakukan untuk mempertahankan kesehatan baik secara fisik maupun fsikologis. Pemenuhan perawatan diri dipengaruhi beberapa faktor, diantaranya: budaya, nilai 
sosial pada individu atau keluarga, pengetahuan tentang perawatan diri, serta persepsi terhadap perawatan diri

Pesantren Ihyaul Ulum sudah menerapkan beberapa aturan-aturan mengenai upaya menjaga lingkungan, khususnya masalah kebrsihan lingkungan di sekitar pesantren diantaranya adalah peraturan yang mewajibkan semua santri untuk membuang sampah pada tempatnya, kewajiban kerja bakti setiap hari jumat pagi, dan dilaksanakannnya piket kebersihan lingkungan dan membuadayakan perilaku kebersihan diri yang sehat. Respon santri sangat baik mengenai kebersihan baik perilaku kebersihan diri maupun kebersihan lingkungan.

\section{Strategi Pengembanagan PHBS dalam Mengantisipasi PBL}

Strategi yang dapat ditempuh dalam pengembangan PHBS yaitu:

1. Strategi promosi kesehatan dengan melakukan kerjasama dengan keluarga dilingkungan pesantren, sehingga sasaran PHBS yang dimulai dari pendekatan individu, keluarga pesantren dan mampu berperilaku hidup bersih dan sehat.

2. Strategi untuk memberikan pengalaman belajar atau menciptakan suatu kondisi bagi santri dengan membuka jalur komunikasi, memberikan informasi dan melakukan edukasi untuk meningkatkan pengetahuan, sikap dan perilaku baik itu bagi pengurus maupun santri

3. Dengan diterapkannya program PHBS diharapkan para santri dan para pengurus serta pengelola pondok pesantrentidak hanya mahir dalam aspek pengembangan moral dan spiritual dengan intlektual yang bernuansa agamis, namun dapat pula menjadi motivator dan innovator dalam perkembangan kesehatan serta menjadi tauladan dalam berperilaku Hidup Bersih dan Sehat(PHBS) bagi para santri

\section{Solusi Permasalahan}

Berdasarkan hasil penelitian yang telah dilakukan di pondok pesantren Ihyaul Ulum Kecamatan Dukun Kabupaten Gresik yang dilakukan melalui teknik promosi kesehatan, observasi dan wawancara, adapun untuk masalah yang terkait penyakit berbasis lingkungan dari santri sudah merasa cukup dan selalu berupaya menerapkannya di kehidupan sehari-hari meski dalam keterbatasan. Maka dapat diuraikan beberapa saran yang dapat digunakan sebbagai salah satu solusi yang dapat diterapkan dalam mengatasi permasalahan dalam penerapan PHBS di Pondok Pesantren Ihyaul Ulum Dukun sebagai berikut: 
1. Meningkatkan komitmen dan kedekatan dari segenap pengurus, pemangkuh, segenap santriwan santriwati dan dinas terkait menggerakkan pola hidup sehat sebagaimana yang termuat dalam program PHBS

2. Memberdayakan para santri dengan cara meningkatkan pengetahuan mereka dalam berperilaku sehat, sehingga mampu menumbuhkan kesadaran dan kemampuan santri dalam berperilaku positif terhadap kesehatan di kehidupan sehari-hari melalui pendekatan/upaya yang belum peranah ditempuh oleh santri-santri sebelumnya

3. Merubah presepsi/ mindset/ paradigma bahwa kesibukan dalam kegiatan di pesantren tidak menjadi penghalang untuk tetap menjaga sanitasi pesantren. Karena kesehatan merupakan asset yang harus dijadikan investasi utama yang harus dipelihara.

\section{SIMPULAN}

Berdasarkan pembahasan diatas dapat disimpulkan bahwa:

1. Tingkat pengetahuan santri Ihyaul Ulum Kecamatan Dukun Kabupaten Gresik santri telah mengetahui mana yang baik untuk kesehatan dirinya, tetapi dalam perilaku masih juga buruk. Hal ini disebabkan karena kebiasaan individu yang berbeda dan mereka menganggap bahwa hal tersebut adalah hal yang biasa.

2. Strategi pengembangan PHBS dalam mengantisipasi PBL yaitu ada 2 strategi, pertama melakukan promosi dan kerjasama, kedua memberikan pengalaman belajar kepada santri

\section{DAFTAR PUSTAKA}

A.S Moenir. 1992. Manajemen Pelayanan Umum di Indonesia. Jakarta : Bumi Aksara

http://eprints.umm.ac.id/25965/2/jiptummpp-gdl-anggernurw-36792-2-babi.pdf diakses pada tanggal 15 April 2019

Ikhwanudin, Alim. 2010. Perilaku Kesehatan Santri. Jurnal Sosial dan Politik.Fakultas Ilmu Sosial dan Ilmu Politik Universitas Airlangga.

Nasyith, Ahmad dzaky.2018. Pola Hidup Sehat di Pondok Pesantren Bahrul Qur'an Jonggrangan Sumberadi Mlati Slema.Universitas Negri Yogyakarta.

Noor, NN., 2006. Pengantar Epidemiologi Penyakit Menular. Jakarta: Rhineka Cipta

Raisya, ririn. 25 November 2016. Kompasiana.Penyakit Berbasis Lingkungan. 